\title{
A PRÁTICA EDUCATIVA DA CONTROLADORIA PÚBLICA
}

\section{ARTIGO DE REVISÃO}

GONÇALVES, Janaína Oliveira ${ }^{1}$

MIRANDA, Maurício Fernando Oliveira de ${ }^{2}$

GONÇALVES JÚNIOR, Edson ${ }^{3}$

GONÇALVES, Janaína Oliveira. MIRANDA, Maurício Fernando Oliveira de. GONÇALVES JÚNIOR, Edson. A Prática Educativa da Controladoria Pública. Revista Científica Multidisciplinar Núcleo do Conhecimento. Ano 05, Ed. 09, Vol. 08, pp. 46-55. Setembro de 2020. ISSN: 2448-0959, Link de acesso: https://www.nucleodoconhecimento.com.br/educacao/controladoria-publica

\section{RESUMO}

Este artigo tem o objetivo de analisar a relevância da Controladoria Pública como órgão de controle e fiscalização da Administração Pública e sua função educativa para a sociedade. A metodologia utilizada neste estudo é a pesquisa bibliográfica, que fundamenta a discussão sobre o tema, a partir dos aportes teóricos que se baseiam em pesquisadores como Meirelles (2000), Filho (2006), Di Pietro (1988), Franco (2015; 2016), Zabala (1988), dentre outros. Destacou-se os principais processos da Controladoria Pública, em que consiste o Controle Interno e a importância de práticas educativas incorporadas à Controladoria. Verifica-se que o Controle Interno Controladoria atua como instrumento democrático de apoio ao cidadão para o Controle Social e que deve representar um papel pedagógico na vida da população,

\footnotetext{
${ }^{1}$ Mestrado em Educação. Pós-Graduação em Metodologia do Ensino Superior; MBA em Gestão de Pessoas; Educação Infantil. Pedagogia.

${ }^{2}$ Mestre em Direito Público; Pós-graduação em Controladoria e Finanças; Contador.

${ }^{3}$ Mestre em Direito Público. Pós-graduação em Direito Público. Direito.
} 
com o intuito de informar e divulgar os processos da gestão pública, levando os cidadãos, a interagirem diretamente com órgão de controle.

Palavras-chave: Controladoria, público, prática educativa.

\section{INTRODUÇÃO}

A Lei 13019 de 31 de julho de 2014, mais conhecida como Marco Regulatório das Organizações da Sociedade Civil foi uma grande conquista nas relações entre o poder público e as Organizações da Sociedade Civil - OSC. Esta lei trouxe inúmeros avanços e aproximação entre estas duas esferas, garantindo parcerias para a realização de políticas públicas. Dentre as inovações apresentadas, uma delas diz respeito à obrigatoriedade do órgão público em capacitar e treinar as OSCs para a realização da prestação de contas e a forma correta de cobrar dos gestores públicos o Chamamento Público e a transparência nos processos. O capítulo II - Da celebração do Termo de Colaboração ou de fomento, na Seção II - Da capacitação de Gestores, Conselheiros e Sociedade Civil Organizada, determina que:

Art. $7^{\circ} \mathrm{A}$ União poderá instituir, em coordenação com os Estados, o Distrito Federal, os Municípios e organizações da sociedade civil, programas de capacitação voltados a:

I - Administradores públicos, dirigentes e gestores;

II - Representantes de organizações da sociedade civil;

III - Membros de conselhos de políticas públicas;

IV - Membros de comissões de seleção;

V - Membros de comissões de monitoramento e avaliação;

VI - Demais agentes públicos e privados envolvidos na celebração e execução das parcerias disciplinadas nesta Lei.

O intuito do legislador ao determinar que tal ação ocorra, é justamente para que os usuários destas informações possam ser capacitados e treinados para prestarem contas de suas ações e para que possam disseminar tal capacitação ao cidadão 
comum. Todavia resta uma dúvida, qual o órgão capaz de fazer tal treinamento e capacitar o cidadão sobre a forma correta de interpretar os dados das prestações de contas? A Câmara Municipal de Vereadores ou a Câmara dos Deputados (Federal e Estadual), o Senado, os Tribunais de Contas Estaduais e o Tribunal de Contas da União, as Controladorias Interna de cada poder? Onde o cidadão poderá pedir ajuda para compreender todo este emaranhado de informações?

\section{CONTROLADORIA PÚBLICA}

Neste estudo vamos nos ater aos processos da Controladoria Pública, contudo, antes de apresentarmos o contexto das funções e atividades dos controles internos e externos devemos entender o que significa o Controle dentro da Administração Pública. De acordo com o professor Hely Lopes Meirelles, "controle, em tema de administração pública, é a faculdade de vigilância, orientação e correção que um poder, órgão ou autoridade exerce sobre a conduta funcional do outro" (MEIRELLES, 2000, p. 264).

Em um conceito bem parecido destacamos que "o controle é um processo de redução do poder, entendida essa expressão no sentido da imposição da vontade e do interesse de um sujeito sobre outrem" (FILHO, 2006, p.745). Para Di Pietro (1998, p.478), o controle na Administração Pública é: "[...] o poder de fiscalização e correção que sobre ela exercem os órgãos dos poderes Judiciário, Legislativo e Executivo, com o objetivo de garantir a conformidade de sua atuação com os princípios que lhes são impostos pelo ordenamento jurídico".

A finalidade precípua de qualquer controle na Administração Pública é de garantir que os gestores administrem os recursos públicos segundo os princípios básicos como: Legalidade, moralidade, impessoalidade, eficiência e outros. Desta maneira podemos compreender que o Controle na Administração Pública nada mais é que uma junção de fatores jurídicos e administrativos, dos quais se pode exercer o poder da fiscalização e verificação da atividade administrativa em qualquer esfera de poder. 
Nestes termos, podemos dividir as formas de controle da Administração Pública em Controle Interno, Controle Externo e Controle Social. Enquanto o Controle Interno é um órgão intra-orgânico, que tem como função fiscalizar e orientar os gestores públicos gerando informações para a tomada de decisão, resguardando por meio de orientações na área contábil, financeira, orçamentária e patrimonial a melhor utilização dos recursos públicos, o Controle externo é exercido por órgãos alheios a Administração Pública. Temos o Controle exercido pelo Poder Legislativo e Poder Judiciário e o Controle Social.

O Controle exercido pelo Poder Judiciário compreende a verificação de atos, processos e atividades que devem estar em acordo com o princípio da Legalidade. Já - Controle realizado pelo Poder Legislativo pode ser dividido em dois ramos, pois temos o controle político e controle técnico, que verifica a questão Contábil, financeira e orçamentária. O primeiro controle é exercido pelas Câmaras Municipais e Estaduais, e pelo Congresso Nacional. Já o controle técnico é exercido pelos Tribunais de Contas, sendo que o Tribunal de Contas da União atua na esfera Federal e os Tribunais de Contas Estaduais na esfera Estadual e Municipal.

O Controle Social, basicamente, é o acompanhamento e fiscalização exercidos pelos cidadãos em relação à aplicação dos recursos públicos administrados pelos gestores públicos, em todas as esferas. O controle Social inicia, ou ao menos deveria iniciarse, antes mesmo da aplicação destes recursos na administração. Entende-se que o cidadão deva buscar, através de instrumentos como os conselhos deliberativos e audiências públicas, a participação na confecção dos orçamentos públicos, ou seja, quando as Leis de Diretrizes orçamentárias e a Lei Orçamentária anual forem levadas a votação nas respectivas câmaras municipais, estaduais ou federal, o cidadão, pode a partir de este momento fazer valer o seu dever junto as organização das atividades públicas de forma democrática.

\section{O CONTROLE INTERNO}

A Constituição Federal da República apresenta claramente a função que cabe aos Controles Internos das entidades. O Artigo 31 da Carta Magna apresenta: 
Art. 31. A fiscalização do Município será exercida pelo Poder Legislativo Municipal, mediante controle externo, e pelos sistemas de controle interno do Poder Executivo Municipal, na forma da lei.

Pode-se verificar a referência sobre Controladorias Públicas na Lei 4.320/64, em seu capítulo II, com o título "do Controle Interno". Tal Lei é ordinária e foi recepcionada pela Constituição da Republica de 1988. A menção ao Controle Interno da referida Lei, bem como a própria Constituição, não demonstra outros atributos tão importantes e funcionais que as Controladorias Internas devem possuir e realizar. Não houve neste momento a proeza do legislador de evidenciar os Controles Internos como um órgão de assessoramento ao gestor.

Com o advento da Lei Suprema em 1.988, foi apresentada explicitamente a função que deve ser realizada através das Controladorias Internas. O STF - Supremo Tribunal Federal, corrobora com o entendimento de que as Controladorias Internas tem por obrigação a fiscalização dos atos dos gestores executivos, conforme descreve o Ministro Ricardo Levandowski, na RMS - Recurso Ordinário em Mandato de Segurança 25.943 do Distrito Federal.

Cada órgão público deve obrigatoriamente possuir um Sistema de Controle Interno, que trabalhe de forma independente, fiscalizando os atos dos gestores e reportando aos Tribunais de Contas qualquer irregularidade que possa existir. A falta do Controle Interno nas entidades públicas é um desrespeito a Constituição Federal e pode acarretar multa e sanções para os gestores públicos, conforme pode ser conferido em diversas decisões dos Tribunais de Contas espalhados pelo Brasil. A aprendizagem é uma construção pessoal, contudo, ocorre quando há um sujeito aprendiz e quem ensina. Nesta perspectiva, a Controladoria pode exercer um papel pedagógico no tocante às suas práticas, rotinas e função, uma vez que a instrução à população possa ser incorporada às suas ações cotidianas. A Controladoria, como órgão fiscalizador municipal, ao adotar uma postura pedagógica, tende disseminar às informações, seja por meio de cartilhas, palestras, propagandas, divulgação audiovisual, entre outras; o que colabora diretamente para a compreensão, orientação e reflexão do cidadão a respeito da relevância do Controle Interno para o município, bem como, a maneira adequada de realizar a análise dos dados disponíveis à população. 


\section{A PRÁTICA EDUCATIVA NA CONTROLADORIA INTERNA}

Podemos considerar que para exercer um papel educativo, torna-se necessário incorporar à Controladoria, um setor pedagógico, que se ocupe de planejar, elaborar e executar projetos que tenham o objetivo de orientar à população a respeito dos processos e dados que são gerados pela Controladoria. Em parceria com outras Secretarias, como a Secretaria de Comunicação, o setor de práticas educativas da controladoria divulgaria suas práticas no intuito de instruir e ensinar aos cidadãos como proceder no acompanhamento e fiscalização de cada setor público. Instrumentos como entrevistas estruturadas, pesquisa de opinião e questionários, por exemplo, podem ser recursos utilizados pela equipe da Controladoria, a fim de realizarem um levantamento dos conhecimentos prévios acerca do órgão fiscalizador, conforme concepção da população. Essa seria uma forma de alinhar os anseios e percepções do povo às atribuições da Controladoria. A partir deste levantamento prévio, estratégias utilizadas nesta pesquisa são apresentados dados suficientes para que se possa elaborar um plano de ação, que tenha como objetivo a aprendizagem da população no que se refere às práticas do Controle Interno e, sobretudo, que ocorra uma reflexão a respeito dos processos, de forma que o cidadão exerça seu direito de reivindicar procedimentos eficazes dos gastos do dinheiro público. É importante considerar que "o campo da intervenção pedagógica é tão rico, tão complexo e tão dinâmico, que provoca a discussão e o debate entre posturas às vezes coincidentes, às vezes discrepantes" (ZABALA, 1998, p. 9). Sendo assim, à prática educativa da controladoria leva ao levantamento de questões, análises, confrontos, debate e reflexão. Se o papel da controladoria é fiscalizar, controlar e fomentar a transparência da gestão pública, torna-se também fundamental, criar estratégias de como promover o ensino do ato de fiscalizar, de como o povo deve exercer o seu papel de acompanhar os processos, certificando-se se de fato as condutas adotadas e desenvolvendo o efetivo controle social.

Consideramos que um setor pedagógico, aqui entendido, como um setor educativo da controladoria, se ocupe de pensar no que ensinar à população a respeito do Controle Interno. Desta forma, devemos considerar que a seleção de conteúdos é fundamental, 
"conteúdos de natureza muito variada: dados, habilidades, técnicas, atitudes, conceitos" (ZABALA, 1998, p.30), que dizem respeito aos procedimentos adotados pelo órgão público.

Nesta direção, o autor aponta que se torna preponderante no processo de ensino aprendizagem, as seguintes questões: O que se deve saber? Fazer e Ser? Segundo Zabala, (1998), os conteúdos a serem aprendidos pelo sujeito aprendiz pode ser classificados como conceitual, procedimental e atitudinal. Ensinar conceitos requer uma prática voltada à compreensão do significado, sendo um processo de elaboração individual de cada indivíduo. Aqui, entendemos que os conceitos que contemplam os processos da Controladoria precisam sair do senso comum para os cidadãos e ganhar significância, funcionalidade e compreensão de sua aplicação. No tocante ao conteúdo procedimental, torna-se relevante pensar que a aprendizagem deve partir de situações concretas, reais, a fim de que o conteúdo seja assimilado junto a capacidade de poder utilizá-lo. Ou seja, não basta saber as informações liberadas pelo Controle, mas torna-se necessário saber qual a funcionalidade e aplicabilidade prática de tais informações, quais os impactos e implicações à sociedade. De caráter mais complexo que os demais, os conteúdos atitudinais, dizem respeito ao conhecimento dos valores, normas e as atitudes. Fazem parte da aprendizagem deste conteúdo as habilidades para a realização de ações que envolvam a participação ativa, reflexão crítica, autonomia, administração de conflitos, posicionamentos e tomadas de decisão com fundamentação de causa. Não basta que o cidadão faça críticas infundadas, torna-se fundamentalmente importante tomar atitudes que os conduza às denúncias, as reivindicações, mas que estejam fundamentadas e a serviço da coletividade e, não, a serviço do individual ou com cunho partidário.

Cabe a Controladoria, criar propostas de ensino que apresentem diferentes oportunidades de aprender, com uma diversidade de meios e recursos, no intuito de promover a divulgação dos conceitos provenientes do Controle Interno, dos procedimentos adotados pelo órgão público, assim como atitudes provenientes da atuação dos servidores públicos, em parceria com a população. 
Segundo Franco, (2015, p. 613), "as práticas, para operarem, precisam do diálogo fecundo, crítico e reflexivo que se estabelecem entre intencionalidades e ações". Levando em conta este pressuposto, consideramos que a Controladoria, ao operar com um setor pedagógico, deve estabelecer um trabalho com intencionalidade. É a intenção de promover a divulgação dos dados e a execução dos processos, que são públicos, que garantirá a transparência dos serviços prestados. A prática adotada pelo Controle não pode ser qualquer prática, é crucial que a proposta esteja voltada para uma prática tecida pedagogicamente, no sentido de práxis, ou seja, um fazer reflexivo e dialógico. Ainda em Franco, (2015), podemos compreender que

as práticas são da ordem da práxis, permeadas pela contradição, interpostas pelos movimentos de ruptura e conservação. Somente as práticas vivenciadas no coletivo e pedagogicamente estruturadas podem dar sentido aos processos de ensino-aprendizagem (FRANCO, 2015, p. 613).

Desta forma, o processo de ensino-aprendizagem pretendido pela Controladoria deve adotar esta perspectiva, de forma que possa contribuir com o desenvolvimento do senso crítico do cidadão, pautando-se em pressupostos técnicos, que os permitam dialogar com o órgão de controle e acompanhar os processos que são realizados em prol do munícipio.

Nesta perspectiva, o olhar é lançado para a melhoria das práticas pedagógicas da Controladoria, para a necessidade de formação dos cidadãos, para a clareza da função do órgão de controle, para qualidade dos procedimentos que são desenvolvidos e para os recursos de ensino e divulgação que são utilizados. Sendo assim, torna-se necessário se ater as seguintes considerações:

a) A formação da população: Um dos maiores desafios, no curto, médio e longo prazos está, sem dúvida, relacionado à formação dos cidadãos, em especial, ao que se refere aos procedimentos da Controladoria Municipal.

b) A função da Controladoria: O papel do Controle Interno, seu funcionamento, o acesso à população e a perspectiva coletiva, como espaço de controle e transparência das contas públicas. 
c) A metodologia de ensino e as práticas educativas da Controladoria: Refletir sobre as práticas pedagógicas e as metodologias de ensino remete à medidas que podem implicar melhor na aprendizagem dos cidadãos. Pensar em atitudes e condutas que tornem o processo educativo mais enriquecedor, de modo a fazer uma constante análise de qualidade dos processos internos.

d) Os recursos didáticos e de divulgação: Os recursos didáticos utilizados no se constituem como importantes ferramentas na melhoria do processo de ensino e aprendizagem, ao passo que contribuem para a ação de mediação entre o cidadão e a Controladoria. O uso dos recursos didáticos e de divulgação podem ser largamente utilizados de modo que enriqueça as discussões facilitando a compreensão dos processos.

Sendo assim, torna-se relevante considerar as diversidades e pluralidades de informações contidas na Controladoria, bem como dos processos, que são traduzidos em inúmeros desafios presentes e que precisam estar claros e precisos para a compreensão da população. Tratar os dados da Controladoria de forma pedagógica é considerar a "pedagogia como prática social, que oferece/impõe/propõe/indica uma direção de sentido às práticas que ocorrem na sociedade, realçando seu caráter eminentemente político" (FRANCO, 2016, p. 537).

\section{CONSIDERAÇÕES FINAIS}

Levando em consideração o que foi apurado, este trabalho consistiu em aprimorar a veracidade do tema proposto inicialmente, ou seja, a Controladoria Interna Municipal como instrumento democrático de apoio ao cidadão para o Controle Social. Restou comprovado que a maior parte dos pesquisados certifica que a Controladoria Interna pode e deve representar um papel pedagógico na vida da população, instruindo e capacitando para a compreensão das informações do accountability. Com esta nova visão, melhorar o controle social, fiscalizando com ênfase as ações e a gestão apresentada pelos administradores públicos. 
Outro fator predominante apontado pelos resultados, foi o de que a Controladoria deve estar mais próxima do cidadão para realizar tal atividade. Este órgão, como já explorado nos capítulos anteriores, deve, por obrigação legal, constar na estrutura administrativa de todos os entes públicos e, partindo desta obrigatoriedade, estar mais próximo da população, uma vez que o acesso a ele é mais rápido e simples. Nesse aspecto, fazer a interface pedagógica entre a Controladoria e a população pode ser considerada uma tarefa diária.

Neste diapasão, o resumo da coleta de dados demonstrou que a Controladoria Interna Municipal do Executivo é o órgão mais propício a executar com maestria as atividades voltadas à capacitação e treinamentos junto à sociedade. É possível unir a Controladoria Interna Municipal ao cidadão para melhorar as atividades de Controle Social, garantindo assim os direitos imputados pela Constituição da República, buscando verificar e fiscalizar intensivamente a boa gestão dos recursos públicos. A ação pedagógica neste contexto possibilita a realização de práticas educativas que contribuem efetivamente com a conscientização da população a respeito do papel da Controladoria Pública, dissemina a divulgação das informações aos cidadãos sobre o Controle Interna. Sobretudo, oferece maior participação e interação à população, pois, bem informados, os cidadãos terão mais condições de acompanhar os processos e cobrar maior transparência dos atos realizados pela gestão pública.

\section{REFERÊNCIAS}

BRASIL. Lei o 13.109 de 31 de julho de 2.104. Estabelece o regime jurídico das parcerias entre a administração pública e as organizações da sociedade civil.). Disponível em: https://www2.camara.leg.br/legin/fed/lei/2014/lei-13019-31-julho2014-779123-normaatualizada-pl.pd. Acesso em: 25 maio 2019.

BRASIL. Constituição (1988). Constituição da República Federativa do Brasil. Disponível:<http://www.senado.gov.br/atividade/const/con1988/CON1988_15.09.201 5/i nd.asp >. Acesso em: 18 março. 2019.

DI PIETRO, Maria Sylvia Zanella. Direito Administrativo. São Paulo: Saraiva, 1998. 
FRANCO, Maria Amélia Santoro. Práticas pedagógicas de ensinar-aprender: por entre resistências e resignações. São Paulo: Educ. Pesquisa. v. 41, n. 3, p. 601 614, jul/set, 2015.

MEIRELLES JÚNIOR, Juliano Candido de. A influência do controller na gestão administrativa.Disponível:http://www.aedb.br/seget/arquivos/artigos08/52_A\%20INF LUENCIA\%20DO\%20CONTROLLER\%20NA\%20GESTAO\%20ADMINISTRATIVA.p df Acesso em: 10 abril. 2019.

ZABALA, Antoni. A Prática educativa: como ensinar. Porto Alegre: Artmed, 1998.

Enviado: Setembro, 2020.

Aprovado: Setembro, 2020. 